\title{
Opiniones acerca del Derecto de Propiedad
}

\author{
por Monseñor JOSE DAMMERT BELLIDO, \\ Vice-Rector de la Pontificia Universidad Católica del Perú.
}

Con motivo del llamado del Abate Pierre para dar vivienda a los sin techo, se ha producido en París $y$ otros lugares de Francia invasiones organizadas de casas desocupadas para dar habitación a quienes carecían de ella o vivían en condiciones infra-humanas.

Los dueños de las casas tomadas por los "squatters" (invasores) han recurrido a los tribunales solicitando protección de sus derechos $y$ por otra parte el Abate Pierre y sus amigos han recordado la antigua máxima de Cicerón "summum-ius, summa injuria" y que no podía ampararse judicialmente a quienes no usaban de sus bienes.

Era el mismo problema que planteaba hace 10 años el Cardenal Saliége en sus "Menus Propos": I.-_"El derecho de propiedad es un derecho natural secundario. De acuerdo. Todos los hombres tienen ese derecho: muchos no pueden ejercerlo. ¿Por qué? Por que lq regla de oro "ni más, ni menos", no ha sido observada. "Ni quien había recogido mucho tuvo de más, ni quien recogiera poco tuvo de menos" (Exodo XVI, 18). II.- "EI Derecho de propiedad es un derecho natural secundario. De acuerdo. ¿Es de derecho natural que se posea 500 hectáreas? "Todos propietarios", dice el Papa Pío XII. Nunca será así, si no se limita el derecho de propiedad. Es en virtud del ćerecho natural, o bien en virtud del derecho civil que poseo 500 hectáreas? Jurisconsultos $\mathrm{Y}$ profesores de moral tienen la palabra".

En defensa de la tesis promulgada por el Abate Pierre, un Vocal de la Corte de Apelaciones de Colmar, el Dr. C. Laplatte, ha publicado un interesante folleto titulado "Les Squatters et le Droit", con prefacio de Daniel Rops, de la Academia Francesa, acerca de la limitación del derecho de propiedad frente al bien común. Teoría que va en contra de Ia tradicional concepción de la propiedad que arranca del derecho romano $y$ es vigorosamente sostenida por el individualismo reinante en la ciencia jurídica de los países liberales y capitalistas.

En Roma y cito las palabras de un eximio profesor alemán, Fritz Schultz, "la determinación del contenido como la tutela jurídica de la propiedad es organizada individualmente. La "rei vindicatio" no se detiene frente a quien adquiere de buena fe, a pesar que el interés de la colectivi. dad, que es él de la libre circulación de los bienes, debería conducir a tutelarlo" ("Prinzipien des römischen Rechts", trad. ital. 1946 pág. 134-5). 
Ia defensa de la propiedad individual es sostenida al extremo y los juristas modernos recogen complacidos los principios romanos.

Mas olvidan que una de las excelencias del derecho romano fue su universalización al adaptarse a todos los pueblos del orbe en el Bajo Imperio $y$ en este período encontramos dos textos legales que constituyen un valioso antecedente para los partidarios del Ảbate Pierre.

Los emperadores Valentiniano, Teodosio y Arcadio en una constitución general dirigida al Prefecto del pretorio de Oriente, entre los años 388 y 392 , determinan que en el caso que el propietario de un-fundo, situado en los confines del Estado, lo abandona y otro toma posesión de él y lo cultiva, trascurridos dos años no puede ejercer más la reivindicación contra el poseedor, quien adquiere después de dos años la propiedad del fundo ocupado (Código Justiniano XI, 59,8).

La finalidad radica en favorecer el cultivo de los campos en una época en que, por la incertidumbre de las invasiones germanas, se recela de trabajar pues se teme perder el producto de todos los esfuerzos.

Unos años más tarde, el año 400, los emperadores Arcadio y Honorio en constitución dirigida también al mismo magistrado, establecen que el propietario, que haya abandonado un fundo ante la imposibilidad de pagar los impuestos, sea invitado a regresar en el término le 6 meses; trascurrido este plazo, el poseedor que se compromete a pagar los impuestos, adquiete la propiedad (idem. XI, 59,11).

Los autores contemporáneos al comentar estas leyes la califican como "una expropiación" (ARANGIO-RUIZ, Instituzioni di diritto romano, IV ed., 1937 pág. 190) o que "Ia adquisición no sucede por usucapión, pues de este instituto no se tiene ni los plazos ni los requisitos, sino por ocupación, pero que no se recliza inmediatamente, sino después de dos años" (BIONDI, Istituzioni di dirito romano, II ed. 1952, pág. 210 n. 16).

En ambos casos se justifica la intrusión en los campos abandonados sea por que se consideren como "res derelictae" equiparadas a las "res nullius" y susceptibles de adquisición por obra del primer ocupante, o que la ley otorgue el título de propiedad.

En las circnstancias' contemporóneas se actualizan estos decretos en relación con las viviendas desocupadas por la urgencia que tiene la sociedad de habitación digna para todas las personas humanas.

En alguna legislación contemporánea, como en la Carta del Trabajo (art. IX) del régimen fascista, se reprodujo el contenido de las constituciones imperiales de fines del siglo IV, para dar tierras de labranza a los campesinos que carecian de ellas e impedir la existencia de latifundios improductivos.

Para los cristianos la actitud del Abate Pierre se justifica con las siguientes palabras de la primera epístola del apóstol San Pedro: "Ante todo mantened tensa la caridad unos con otros, porque "la caridad cubre la muchedumbre de los pecados" (Proverbios 10, 12; ejerced amorosa hospitalidad los unos con los otros, sin murmuración; cada cual, conforme al don que recibió, servid con él a los demás, como buenos administradores de la multiforme gracia de Dios" $(4,8-10)$. 